\title{
Sistem Informasi Geografis Coffee Shop di Kota Samarinda Berbasis Web
}

\author{
Rofikhotul Khoeriyah \\ Teknologi Geomatika, Politeknik Pertanian Negeri \\ Samarinda, Samarinda, 75131 \\ rofikhotul7@gmail.com
}

\author{
Nia Kurniadin* \\ Teknologi Geomatika, Politeknik Pertanian Negeri \\ Samarinda, Samarinda, 75131 \\ niakurniadin@politanisamarinda.ac.id \\ *Corresponding author
}

\begin{abstract}
Abstrak-Coffee Shop merupakan tempat yang banyak diminati oleh masyarakat Kota Samarinda. Terdapat beberapa perbedaan antara Coffee Shop dengan kedai kopi atau warung kopi, antara lain dari segi konsep, desain interior, sarana dan prasarana, menu dan segmen pasar. Akan tetapi masyarakat dihadapkan dengan permasalahan dalam mengetahui lokasi serta informasi yang ada pada Coffee Shop. Dengan demikian diperlukan sarana informasi yang dapat diakses oleh umum, salah satu cara dengan pembuatan peta informasi berbasis Web yaitu WebGIS. Tujuan dari kegiatan penelitian ini yaitu untuk memberikan informasi lokasi dan informasi lainnya tentang Coffee Shop yang ada di Samarinda, serta penyajiannya dalam bentuk peta informasi berbasis Web. Data yang dikumpulkan berupa nilai titik koordinat dari hasil pengamatan di lapangan, serta beberapa informasi mengenai Coffee Shop dari media sosial masing-masing Coffee Shop, yang kemudian diolah menggunakan perangkat lunak Quantum GIS menjadi peta informasi berbasis Web. Hasil penelitian menunjukkan bahwa terdapat 49 Coffee Shop yang tersebar di Kota Samarinda dan data tersebut disajikan dalam bentuk WebGIS yang disertai informasi yang ada pada masing-masing Coffee Shop tersebut.
\end{abstract}

Kata Kunci-peta informasi, webgis, coffee shop, samarinda, peta coffee shop, qgis 2 web

\section{PENDAHULUAN}

Gaya hidup masyarakat khususnya kalangan remaja dan dewasa di Kota Samarinda dalam melakukan aktifitas seperti bersosialisasi, bercengkerama santai hingga berisnis dilakukan di luar rumah. Salah satu tempat yang sering dikunjungi dan menjadi tempat favorit untuk kegiatan tersebut adalah Coffee Shop. Kehadiran Coffee Shop menjadi tempat yang paling banyak diminati untuk pertemuan bersama rekan bisnis, bersantai, arisan, serta menjadi tempat diskusi. Saat ini, kebutuhan dan minat terhadap Coffee Shop diiringi dengan peningkatan jumlah Coffee Shop di Kota Samarinda.

Dari peningkatan jumlah Coffee Shop tersebut, masyarakat Kota Samarinda dihadapkan dengan permasalahan dalam mengetahui lokasi, serta informasi yang ada pada Coffee Shop. Ketersediaan informasi Coffee Shop masih terbatas, bahkan tidak sedikit yang masih belum terindeks dalam google maps saat melakukan pencarian dengan kata kunci Coffee Shop.

Teknologi informasi yang diintegrasikan dengan teknologi berbasis geografis yang sering disebut SIG (Sistem Informasi Geografis), diharapkan dapat menjadi salah satu solusi yang dapat dimanfaatkan dalam menyajikan informasi Coffee Shop yang ada di Kota Samarinda. SIG dibuat dengan menggunakan informasi yang berasal dari pengolahan sejumlah data, yaitu data geografis atau data yang berkaitan dengan posisi obyek dipermukaan bumi. Teknologi SIG mengintegrasikan operasi pengolahan data berbasis database yang biasa digunakan saat ini, seperti pengambilan visualisasi yang khas serta berbagai keuntungan yang mampu ditawarkan analisis geografis melalui gambar-gambar petanya. Selain perkembangan teknologi yang semakin pesat, teknologi juga sangat dibutuhkan oleh masyarakat salah satunya mengenai teknologi yang berisi tentang informasi suatu tempat yang ada di Indonesia khususnya Kota Samarinda.

Berdasarkan permasalahan dan salah satu teknologi yang dapat digunakan di atas, penulis memandang perlu melakukan penelitian tentang sebaran Coffee Shop di Kota Samarinda menggunakan teknologi Sistem Informasi Geografis berbasis Web.

\section{STUDI PUSTAKA}

Menurut Kamus Besar Bahasa Indonesia, Departemen Pendidikan dan Kebudayaan, Café atau Coffee Shop adalah suatu tempat (kedai) yang menyajikan olahan kopi espreso dan kudapan kecil. Seiring perkembangan jaman, coffee shop menyediakan makan kecil danbmakanan berat (KBBI, 1988). Istilah kata cafe berasal dari bahasa Perancis yang berarti kopi. Orang Perancis menyebut kedai kopi dengan istilah cafe. Perancis menjadi salah satu Negara yang dijuluki "Negri Cafe" karena pesatnya perkembangan cafe di sana dan dari Perancis lah Cafe mulai tersebar luas di dunia (Ukers, 2012).

Warung kopi dan kafe menjadi tempat-tempat yang sering dikunjungi untuk tempat ngopi dan nongkrong. Di setiap sudut kota kita sering menjumpai kedai kopi dan kafe yang selalu ramai akan pengunjung. Warung kopi biasa disebut sebagai kedai kopi, umumnya memiliki konsep yang merakyat dengan harga yang terjangkau. Sedangkan kafe biasa disebut juga sebagai coffee shop, umumnya lebih bergengsi dengan harga yang cenderung lebih mahal (Mustika, 2019). Perbedaan Coffee Shop dan Warung Kopi dapat dilihat dari berbagai sektor, antara 
lain konsep, desain interior, menu yang disediakan, harga, lokasi, segmen pasar dan suasana.

Menurut Suryantoro (2013), Sistem Informasi Geografis merupakan ilmu pengetahuan yang berbasis pada perangkat lunak komputer, yang digunakan untuk memberikan bentuk digital dan analisis terhadap permukaan geografi bumi, sehingga membentuk suatu informasi keruangan yang tepat dan akurat. SIG dapat menggabungkan berbagai jenis data pada satu titik tertentu yang ada di bumi, menghubungkannya, menganalisanya, hingga memetakan hasilnya. Data yang diolah oleh sistem ini adalah data spasial yakni data yang berorientasi pada geografis. Selain itu juga merupakan lokasi yang mempunyai koordinat tertentu.

Maharani et al. (2017) menyatakan bahwa Sistem Informasi Geografis adalah sistem yang berbasiskan komputer yang digunakan untuk menyimpan dan memanipulasi informasi-informasi geografi. SIG dirancang untuk mengumpulkan, menyimpan, dan menganalisis objek-objek dan fenomena dimana lokasi geografi merupakan karakteristik yang penting atau kritis untuk dianalisis. Dengan demikian, SIG merupakan sistem komputer yang memiliki empat kemampuan berikut dalam menangani data yang bereferensi geografi: masukan, manajemen data (penyimpanan dan pemanggilan data), analisis dan manipulasi data, serta keluaran.

Web GIS adalah Sistem Informasi Geografis yang didistribusikan di seluruh lingkungan jaringan komputer untuk mengintegrasikan, menyebarkan, dan mengkomunikasikan informasi geografis secara visual di World Wide Web melalui internet (Riyanto, 2010). WebGIS merupakan aplikasi Geographic Information System (GIS) yang dapat diakses secara online melalui internet / web. Pada konfigurasi WebGIS ada server yang berfungsi sebagai MapServer yang bertugas memproses permintaan peta dari client dan kemudian mengirimkannya kembali ke client. Dalam hal ini pengguna / client tidak perlu mempunyai Software GIS, hanya menggunakan internet browser seperti Internet Explorer, Mozilla Fire Fox, atau Google Chrome untuk mengakses informasi GIS yang ada di server.

Beberapa penelitian yang telah dilaksanakan degan memanfaatkan Sistem Informasi Berbasis Web antara lain penelitian yang dilakukan oleh Dewi et al. (2018), Irwansyah \& Khudri (2017), Salam \& Fahmi (2019) untuk pemetaan dan inventarisasi aset pemerintah, Taufik \& Anugraha (2016) untuk inventarisasi dan evaluasi aset bangunan, Maryam \& Handayani (2015) untuk sarana dan prasarana pelabuhan, Tumimomor et al. (2013) untuk pemetaan Pariwisata, Rahman (2019) untuk pemetaan tanah bersertifikat.

\section{Metodologi}

\section{A. Lokasi Penelitian}

Penelitian ini dilaksanakan di Kota Samarinda dan objek yang dikaji ialah Coffee Shop yang ada di Kota Samarinda, sedangkan data lapangan diolah di
Laboratorium Geomatika Program Studi Teknologi Geomatika Politeknik Pertanian Negeri Samarinda.

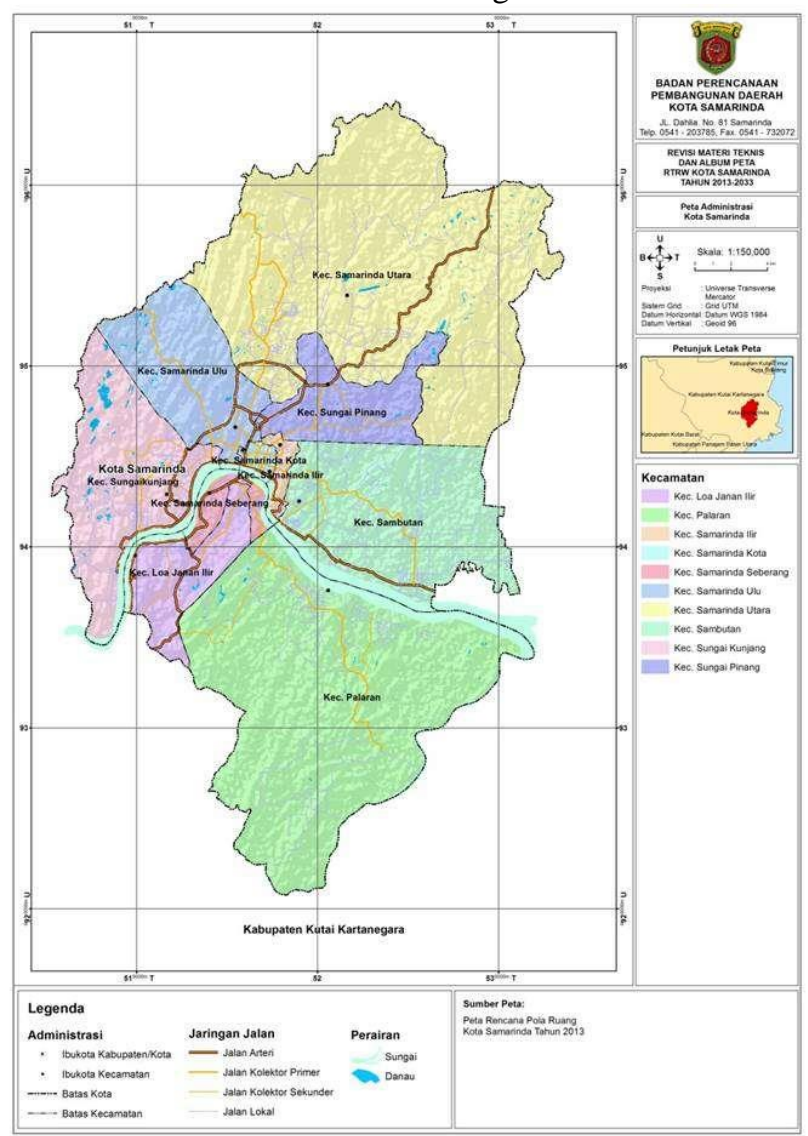

Gambar 1. Lokasi Penelitian

\section{B. Data dan Peralatan}

Data yang digunakan dalam penelitian ini adalah data primer dan data sekunder Coffee Shop yang ada di Kota Samarinda. Data primer berupa titik koordinat yang diperoleh dari hasil pengukuran di lapangan sedangkan data sekunder berupa informasi masing-masing Coffee Shop yang diperoleh dari media sosial Instagram Coffee Shop yang diteliti.

Perangkat keras yang digunakan dalam penelitian ini adalah GPS Garmin 64s Map sebagai alat untuk mengambil data posisi koordinat Coffee Shop, dan kamera digital untuk dokumentasi penelitian. Sedangkan perangkat lunak yang digunakan adalah Map Source untuk memindahkan data koordinat dari GPS ke komputer, Quantum GIS untuk mengolah data penelitian, Notepad++ untuk pembuatan code WebGIS, dan Xampp untuk hosting localhost.

\section{Tahap Pengumpulan dan Pengolahan Data}

Pengumpulan data yang terdiri dari data koordinat dan data informasi masing-masing Coffee Shop yang ada di Kota Samarinda. Data koordinat diperoleh dengan cara mengunjungi masing-masing Coffee Shop dan melakukan marking menggunakan GPS Garmin 64s Map. Sedangkan data informasi masing-masing Coffee Shop diperoleh dengan mengunjungi akun Instagram Coffee Shop tersebut berupa data nama Coffee Shop, alamat, jam 
operasional, fasilitas yang disediakan dan jenis menu serta harga dari masing-masing menu yang tersedia.

Pengolahan data diawali dengan mengunduh data koordinat dari GPS Garmin 64s Map ke perangkat komputer menggunakan perangkat lunak Map Source. Data koordinat diekspor ke dalam format Comma Separated Values (.csv) untuk dapat diolah menggunakan perangkat lunak Quantum GIS.

Data koordinat berformat .csv selanjutnya diolah dan diekspor ke format Shapefile (.shp) menggunakan perangkat lunak Quantum GIS untuk selanjutnya dilakukan editing dan ditambahkan data informasi Coffee Shop beserta foto sebagai data atribut.

Tahap selanjutnya adalah proses layout, dimana pada tahap ini dilakukan manipulasi data yang akan disajikan berupa penambahan peta dasar, mengganti simbologi, dan mengatur tampilan pop-up. Pada pop-up ini diatur data apa saja yang akan ditampilkan ketika simbol dari salah satu Coffee Shop dipilih atau diklik.

Setelah manipulasi tampilan data selesai dilakukan, tahap selanjutnya adalah melakukan ekspor data Coffee Shop ke format WebGIS menggunakan pengaya (plugin) qgis2web yang tersedia dan dapat dipasang pada perangkat lunak Quantum GIS.

Tahap selanjutnya adalah proses pembuatan WebGIS dengan menggunakan editor Notepad++ untuk memperbaiki tampilan WebGIS serta menambahkan beberapa menu dan halaman seperti halaman utama, halaman data, dan kontak. Dilanjutkan dengan tahap pengujian dan upload ke hosting di internet.

\section{HASIL DAN PEMBAHASAN}

Data Coffee Shop yang tersebar di Kota Samarinda yang berhasil dikumpulkan dari pengambilan data di lapangan beserta akun Instagramnya disajikan dalam Tabel 1. Selanjutnya data Coffee Shop tersebut diolah menggunakan perangkat lunak Quantum GIS dan disajikan dalam bentuk WebGIS. Tampilan dari masingmasing halaman WebGIS yang berhasil dibuat disajikan dalam Gambar 2 sampai dengan Gambar 8.

Pada halaman Beranda (Gambar 2), yang merupakan halaman pertama yang pengguna bisa akses menyajikan informasi berupa Caption dan Tagline dari WebGIS yang dibuat. Pada halaman Peta (Gambar 3), yang merupakan halaman inti dari WebGIS ini menyajikan peta informasi sebaran Coffee Shop yang ada di Kota Samarinda. Pada halaman ini disajikan titik-titik posisi atau lokasi Coffee Shop dengan simbol cangkir berwarna hitam. Untuk mengetahui secara rinci informasi dari masing-masing Coffee Shop, dapat dilakukan dengan cara mengklik salah satu simbol cangkir. Informasi rinci ini berupa pop-up (Gambar 4) yang menyajikan informasi Nama, Alamat, Buka-Tutup (Jam Operasional), Minuman (kisaran harga minuman), Makanan (kisaran harga makanan), Fasilitas, Instagram, Photo, dan Rute (diteruskan ke google maps).

Tabel 1. Data Coffee Shop di Samarinda

\begin{tabular}{|c|c|c|c|}
\hline No & Nama Coffee Shop & Alamat & Instagram \\
\hline 3 & Exselsso (Big Mall) & Jl. Untung Suropati & @excelsosamarinda \\
\hline 4 & $\begin{array}{l}\text { h\&m Coffee } \\
\text { Shop }\end{array}$ & JI. Bung Tomo & @ hmcoffeeshop \\
\hline 5 & Coffee Toffee & Jl. Ir. H. Juanda & $\begin{array}{l}\text { @ coffeetoffee.samari } \\
\text { nda }\end{array}$ \\
\hline 6 & MAGARA & Jl. Juanda 1 & @ magara.cafe.carwash \\
\hline 7 & Ruang Teduh & Jl. Juanda 4 & @ ruangteduhcoffee \\
\hline 8 & Triple R & Jl. Juanda 2 & @ tripler_cafe \\
\hline 9 & Troef Coffee & $\begin{array}{l}\text { Jl. Wijaya Kusuma } \\
\text { X }\end{array}$ & @troef_coffee \\
\hline 10 & Insomnia & JI. Wijaya & @insomnia.coffee19 \\
\hline 11 & Salmont & Jl. Durian & @ salmontcoffee \\
\hline 12 & \begin{tabular}{|l} 
Sealand Coffee \\
Shop
\end{tabular} & Jl. Kesuma Bangsa & @ sealandcafe \\
\hline 13 & Republik & Jl. Kesuma Bangsa & @ republikcoffee \\
\hline 14 & Seedy & Jl. Stadion Timur & @ seedy.coffee \\
\hline 15 & Pops & Jl. KH. Agus Salim & @ popcoffee.id \\
\hline 16 & Whynot Coffee & Jl. Pahlawan & @whynotcoffee \\
\hline 17 & Nabo & Jl. Siradj Salman & @ nabo.coffee \\
\hline 18 & Teras Roemah & Jl. MT Haryono & $\begin{array}{l}\text { @ terasroemah.samari } \\
\text { nda }\end{array}$ \\
\hline 19 & $\begin{array}{l}\text { JCO Samarinda } \\
\text { Square }\end{array}$ & $\begin{array}{l}\text { Solaria Samarinda } \\
\text { Square }\end{array}$ & @jcoindonesia \\
\hline 20 & Konus 2.0 & Jl. M. Yamin & @kedaikonus \\
\hline 21 & Rumpi Coffee & Jl. M. Yamin & @ rumpi.coffee \\
\hline 22 & Kopinah & Jl. Perjuangan & @kopinah \\
\hline 23 & KAEL & JI. Seruni & @ kael.espresso \\
\hline 24 & Satu Kata & Jl. Basuki Rahmat & @ satukata.coffee \\
\hline 25 & Ruang Temu & $\begin{array}{l}\text { Jl. A. Wahab } \\
\text { Syahranie }\end{array}$ & @ rute_ruangtemu \\
\hline 26 & Lopecoffee & Jl. Gatot Subroto & @ lopecoffeesmd \\
\hline 27 & Violate Café & Jl. KH. Abul Hasan & @ violate_cafe \\
\hline 28 & Bangi Kopi & $\begin{array}{l}\text { Jl. Pangeran } \\
\text { Diponegoro }\end{array}$ & $\begin{array}{l}\text { @ bangikopi_samarin } \\
\text { da }\end{array}$ \\
\hline 29 & Karma & Jl. Dewi Sartika & @karma.coffee.smd \\
\hline 30 & JCO (Mall SCP) & Jl. Mulawarman & @ jcoindonesia \\
\hline 31 & $\begin{array}{l}\text { Starbucks (Mall } \\
\text { SCP) }\end{array}$ & Jl. Mulawarman & @ starbucksindonesia \\
\hline 32 & $\begin{array}{l}\text { JCO (Mall Plaza } \\
\text { Mulia) }\end{array}$ & Jl. Bhayangkara & @jcoindonesia \\
\hline 33 & $\begin{array}{l}\text { Excelsso (Mall } \\
\text { Plaza Mulia) }\end{array}$ & Jl. Bhayangkara & @excelsosamarinda \\
\hline 34 & Muster Station & Gg. Karya & @ mustertationsmd \\
\hline 35 & Excelso Juanda & $\begin{array}{l}\text { Jl. Ir. H. Juanda } \\
\text { No.90 }\end{array}$ & @excelsosamarinda \\
\hline 36 & KJS Coffee House & Jl.Sirad Salman & @kjs_coffeehouse \\
\hline 37 & Waroeng RK & $\begin{array}{l}\text { Jl. A. W. Syahranie } \\
\text { No.179 }\end{array}$ & @waroeng_rk \\
\hline 38 & Stom Coffee & Jl. Gerilya No.79 & @ stomcoffee \\
\hline 39 & Hachira Coffee & $\begin{array}{l}\text { Jl. Kadrie Oening } \\
\text { No.72 }\end{array}$ & @ hachira.coffee \\
\hline 40 & Kopi Tumin & Jl. M. Yamin No.10 & @ kopitumin_bar \\
\hline 41 & $\begin{array}{l}\text { Tempoe Doeloe } \\
\text { Kopi }\end{array}$ & Jl. PM.Noor No.8 & $\begin{array}{l}\text { @ kedaikopitempoedo } \\
\text { eloe }\end{array}$ \\
\hline 42 & Kopi Diawan & $\begin{array}{l}\text { Jl. Kadrie Oening } \\
\text { No.54 }\end{array}$ & @kopidiawan \\
\hline 43 & FR Coffee & \begin{tabular}{|l|} 
Jl. Perum Bumi \\
Sempaja blok EA \\
No.91
\end{tabular} & @fr.coffee \\
\hline 44 & Hero Coffee & Jl. Pahlawan No.26 & @ coffeehero_smr \\
\hline 45 & Aksara Kopi Buku & $\begin{array}{l}\text { Jl. Merdeka Timur } \\
\text { No.2 }\end{array}$ & @aksara_kopibuku \\
\hline 46 & At.cong & Jl. Gerilya No.11 & @at.cong \\
\hline 47 & Metro Coffee & Jl. Nahkoda No.84 & @ metrocoffee.kitchen \\
\hline 48 & D’Orange Cafe & Jl. M. Yamin No.37 & @ dorangecoffee \\
\hline 49 & Cultuur Volk & J1. M Yamin No.72 & @ cultuurvolk \\
\hline
\end{tabular}




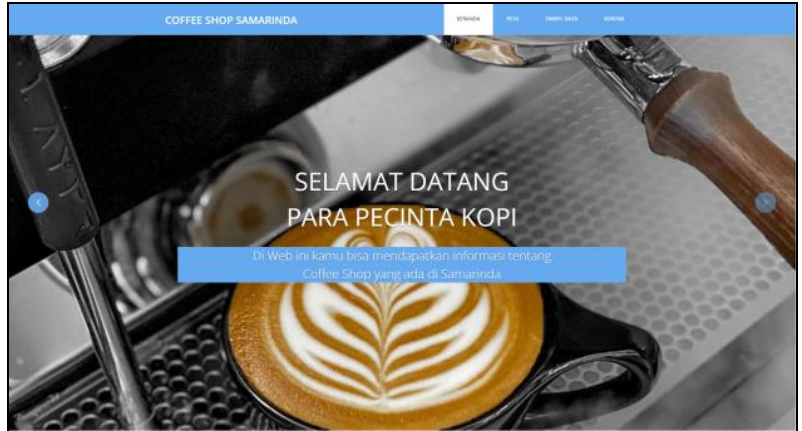

Gambar 2. Halaman Beranda

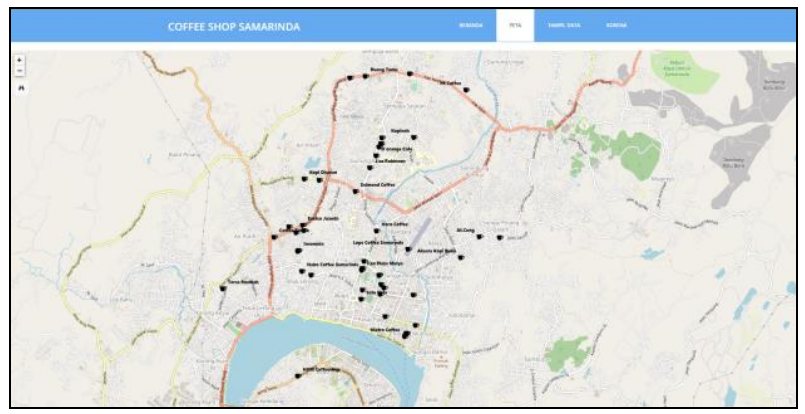

Gambar 3. Halaman Peta

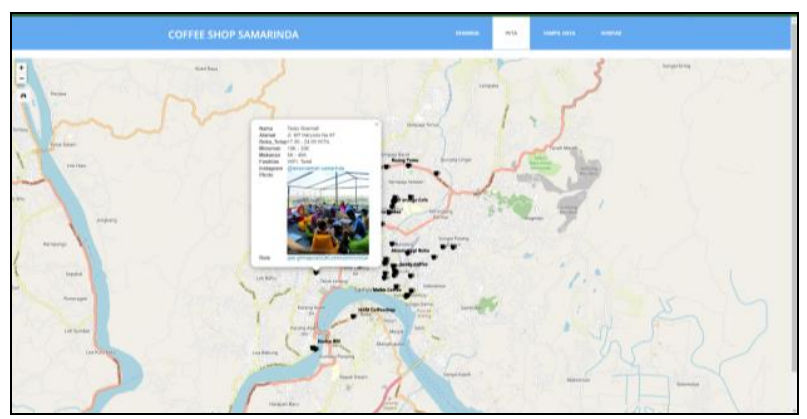

Gambar 4. Tampilan Pop-up

Untuk mengetahui instagram dari Coffee Shop ini cukup dengan mengklik link/tautan instagram pada $\neg$ pop-up dan akan diteruskan ke halaman instagramnya (Gambar 5). Demikian juga untuk mengetahui rute dari posisi pengguna ke alamat Coffee Shop dengan cara mengklik link/tautan Rute yang selanjutnya akan diteruskan ke halaman google maps (Gambar 6) atau ke aplikasi google maps jika menggunakan smartphone.

Pada halaman Tampil Data (Gambar 7), disajikan informasi data Coffee Shop dalam bentuk tabel, yang berisi infomasi Nama Coffee Shop, Alamat Coffee Shop, Jam Operasional, Fasilitas, dan Akun Instagram. Sedangkan pada halaman Kontak (Gambar 8), disajikan informasi dari pengembang Aplikasi WebGIS, yang terdiri dari foto, nama, alamat, nomer telpon/hp, alamat email, akun instagram, dan keterangan.

Berdasarkan hasil penelitian dan analisis sebaran Coffee Shop yang ada di Kota Samarinda, diperoleh informasi bahwa sebaran Coffee Shop masih terpusat pada wilayah pusat kota yang mana pada wilayah tersebut terdapat pusat perbelanjaan/Mall, perkantoran dan Hotel, sehingga keberadaan Coffee Shop cenderung bersifat mendekati atau berada di sekitar tempat-tempat tersebut.

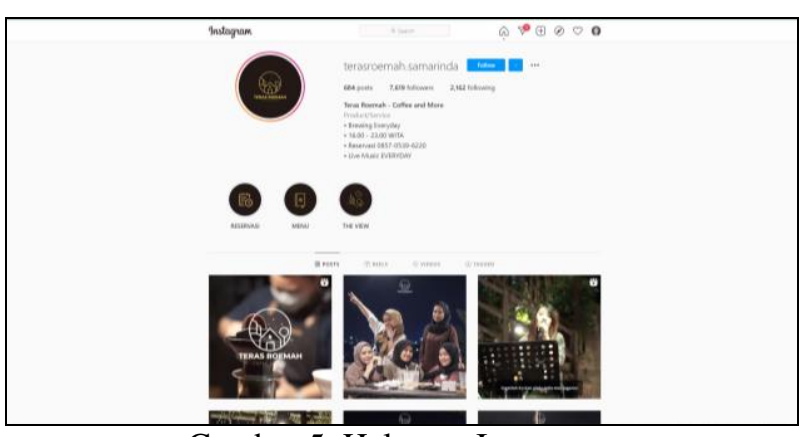

Gambar 5. Halaman Instagram

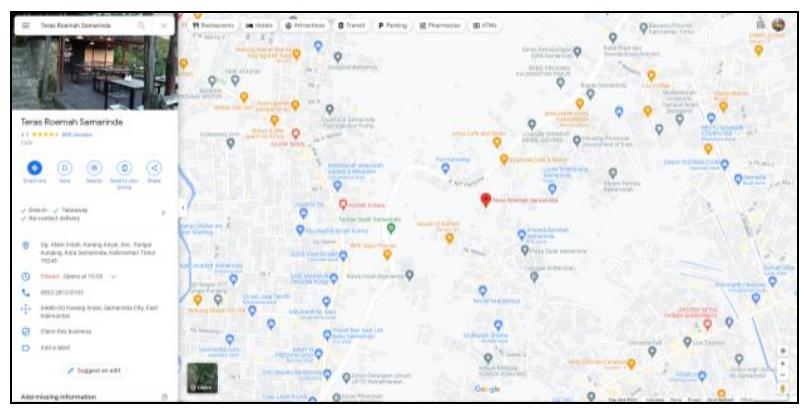

Gambar 6. Halaman Rute Google Maps

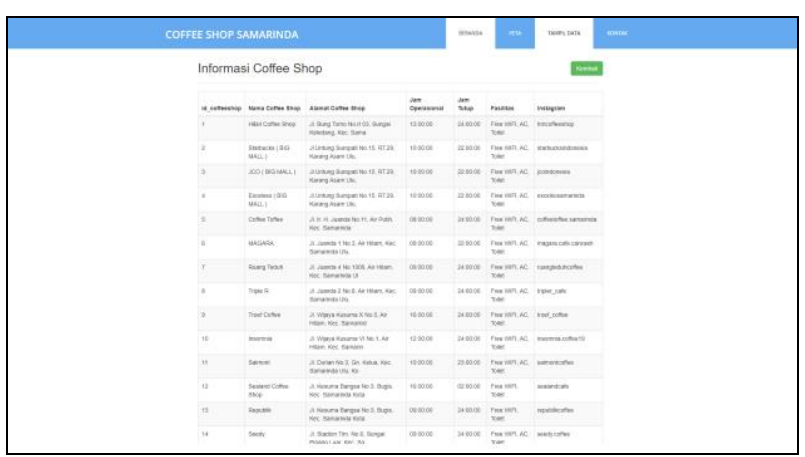

Gambar 7. Halaman Tampil Data

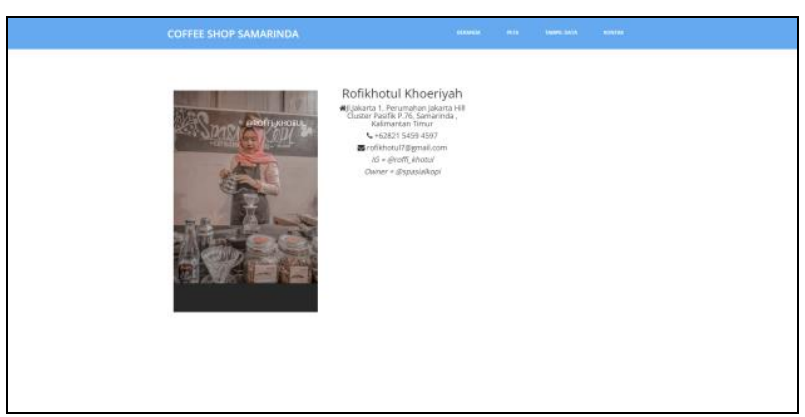

Gambar 8. Halaman Kontak

\section{KESIMPULAN}

Berdasarkan hasil penelitian yang dilaksanakan dapat disimpulkan bahwa terdapat 49 Coffee Shop yang tersebar di Kota Samarinda dan data tersebut disajikan dalam bentuk WebGIS yang disertai informasi yang ada pada masing-masing Coffee Shop tersebut antara lain nama Coffee Shop, alamat, jam operasional, harga, fasilitas, instagram, rute, dan foto Coffee Shop. Peta informasi Coffee Shop di Kota Samarinda berbasis WebGIS dapat diakses melalui tautan https://s.id/coffeeshopsamarind 


\section{DAFTAR PUSTAKA}

Dewi, M. S., Hariyanto, T., \& Kurniawan, A. (2018). Inventarisasi Aset Pemerintah di Luar Peta Area Terdampak Lumpur Sidoarjo Sesuai Perpres No. 33 Tahun 2013 Menggunakan Web GIS. Geoid, 13(2), 181-186. https://doi.org/10.12962/j24423998.v13i2.3880

Irwansyah, \& Khudri, A. (2017). GIS Aset Pemerintah di Provinsi Sumatera Selatan (Studi Kasus Aset Pemerintah Kabupaten Prabumulih). Jurnal Ilmiah MATRIK, 19(2), 121-130.

KBBI. (1988). Arti Kata Kafe. Jakarta. Balai Pustaka.

Maharani, S., Apriani, D., \& Kridalaksana, A. H. (2017). Sistem Informasi Geografis Pemetaan Masjid di Samarinda Berbasis Web. Jurnal Informatika, $11(1)$, 9-20. https://doi.org/10.26555/jifo.v11i1.a5205

Maryam, R. A., \& Handayani, H. H. (2015). Studi Pengembangan WebGIS Sarana dan Prasarana Pelabuhan (Studi Kasus: Tanjung Perak Surabaya). Geoid, 10(2), 120-128.

Mustika, S. (2019). 7 Perbedaan Warung Kopi (Kedai Kopi) dan Kafe (Coffee Shop).
Rahman, L. (2019). Sistem Informasi Geografis Tanah Bersertifikat pada Desa Suluk Berbasis Web. Seminar Nasional Teknologi Informasi Dan Komunikasi, 37-44.

Riyanto. (2010). Sistem Informasi Geografis Berbasis Mobile. Yogyakarta: Penerbit Gaya Media.

Salam, A. A., \& Fahmi. (2019). Sistem Informasi Geografis Pemetaan Aset Daerah Menggunakan Algoritma Djikstra di BKD Kota Cirebon. Information Technology Journal (INTECH) of UMUS, 1(1), 45-55.

Suryantoro, A. (2013). Integrasi Aplikasi Sistem Informasi Geografis. Yogyakarta Ombak.

Taufik, M., \& Anugraha, A. S. (2016). Aplikasi Sistem Informasi Geografis untuk Inventarisasi dan Evaluasi Aset Bangunan Milik Pemerintah Kota Surabaya (Studi Kasus: Surabaya Pusat). Geoid, 12(1), 43-47. https://doi.org/10.12962/j24423998.v12i1.2394

Tumimomor, M., Jando, E., \& Meolbatak, E. (2013). Sistem Informasi Geografis Pariwisata Kota Kupang. Jurnal Nasional Pendidikan Teknik Informatika (JANAPATI), 1(2), 142-152. https://doi.org/10.23887/janapati.v2i2.9785

Ukers, W. H. (2012). All About Coffee. USA. Adams Media. 